\title{
VECINOS, CIUDADANOS Y PATRIOTAS: LOS COMITÉS PATRIÓTICOS Y EL ESPACIO-TEMPORALIDAD DE OPOSICIÓN AL NEOLIBERALISMO EN COSTA RICA ${ }^{1}$
}

\section{NEIGHBORS, CITIZENS AND PATRIOTS: THE COMITÉS PATRIÓTICOS AND THE SPATIOTEMPORALITY OF OPPOSITION TO NEOLIBERALISM IN COSTA RICA}

\author{
Jeremy Rayner
}

RESUMEN

Los Comités Patrióticos surgieron en Costa Rica en el contexto de un histórico referéndum sobre el Tratado de Libre Comercio con los Estados Unidos. Esta ponencia presenta un análisis de este movimiento, basado en un año de investigación etnográfica. Enfoco en las cuestiones de espacio-temporalidad y escala política, para iluminar como este movimiento ha intentado articular una nueva estructura política que actuaría al mismo tiempo en escalas locales y en la escala nacional en aras de enfrentar al proyecto neoliberal durante $y$ después del referéndum.

PALABRAS CLAVE: COSTA RICA * MOVIMIENTO SOCIAL * NACIONALISMO * GOBIERNO LOCAL $*$ NEOLIBERALISMO $*$ TRATADO DE LIBRE COMERCIO

ABSTRACT

The Comités Patrióticos emerged in the context of the historic referendum on the Free Trade Agreement with the United States. This paper offers an analysis of this movement based on a year of ethnographic research. I focus on questions of spatiotemporality and political scale, in order to illuminate how this movement has attempted, during and after the referendum, to articulate a new political structure capable of acting at once on local and national scales in order to challenge the neoliberal project.

KEYWORDS: COSTA RICA * SOCIAL MOVEMENT * NATIONALISM * LOCAL GOVERNMENT $*$ NEOLIBERALISM $*$ FREE TRADE

El artículo proviene de una investigación mayor financiada por el Doctoral Dissertation Fieldwork Grant del Wenner Gren Foundation y el Doctoral Dissertation Improvement Grant del National Science Foundation. Quiero agradecer a Valeria Morales, Adriana Méndez, y Estibaliz Hidalgo cuyo trabajo ha contribuido a este proyecto, a Ciska
Raventós por sus múltiples aportes, $y$ a la gente de los Comités Patrióticos por posibilitar esta investigación.

* Candidato al Doctorado en Antropología. Graduate Center, City University of New York.

jcrayner@gmail.com 
Desde mediados de los noventa la política de Costa Rica se ha caracterizado por un aumento en las manifestaciones del descontento en torno a la neoliberalización. Un aspecto importante de este aumento ha sido la red de "Comités Patrióticos" que surgió, en un principio, como oposición al Tratado de Libre Comercio con los Estados Unidos, Centroamérica y la República Dominicana (TLC o CAFTA-DR) en el marco del primer referéndum efectuado en la historia del país. En este artículo presento algunas reflexiones sobre este movimiento, basado en un año de observación participante en las innumerables reuniones, charlas, asambleas, volanteos, y manifestaciones que realizaron los Comités Patrióticos entre agosto de 2007 y septiembre de 2008. Mi mayor participación ha sido con dos comités ubicados en los barrios populares de la zona sur de San José, y en un menor grado con varios comités en Montes de Oca, Heredia, y Guanacaste. En este artículo, considero este movimiento en relación con los temas de la organización y representación del espacio y del tiempo. Sugiero que este enfoque sirve para iluminar gran parte de lo que ha sido importante, distinto, e innovador en la práctica política de los Comités $\mathrm{Pa}$ trióticos.

Empleo como herramienta analítica principal, el concepto de escala del geógrafo Neil Smith, el cual propone que la diferencial extensión espacial de los procesos sociales y materiales fundamentales crea escalas distintas. En el capitalismo estas escalas incluyen el globo, la región, la nación, el área urbana, el barrio, el hogar, y el cuerpo (Smith, 1984; Smith y Marston, 2001). Pero esta organización de escala es dinámica; su constante reconfiguración constituye un eje de la política (la "globalización" es precisamente un cambio en el orden de escalas), y la organización de escalas expresa las relaciones de poder entre clases. El poder de las clases dominantes se fundamenta en la capacidad de actuar a escalas mayores $y$ de estructurar las relaciones entre escalas (Smith, 1984 y 1992; Swyngedouw, 1997; Brenner, 1999; Smith y Marston, 2001; Smith, 2004; véase también Lomnitz Adler, 1992). El clientelismo es la manera de manejar relaciones entre escalas; como funciona por la creación de relaciones de dependencia entre individuos 0 pequeños grupos $y$ actores poderosos vinculados con el estado nacional, el clientelismo depende de, $y$ contribuye a, la ausencia de organizaciones autónomas capaces de hacer reclamos unificados en el nombre de agrupaciones amplias (véase Lomnitz Adler, 1992; Auyero, 2000; Tilly, 2007: 96-7).

Al mismo tiempo, planteo que la política de escalas es siempre también una política de temporalidades. El globo, la nación, y el barrio se representan y experimentan en tiempos distintos (véase Chatterjee, 2004: 3-25). Representaciones del tiempo han sido ejes de la controversia pública en torno a la transnacionalización y la liberalización en Costa Rica: tiempos de progreso y estancamiento, tiempos globales imponentes, tiempos de historia heroica, tiempos de deliberación democrática. Pero, a la vez, detrás de estos tiempos nacionales y globales de la cultura pública hay otras temporalidades, como los tiempos de las vidas y los tiempos de los barrios, que también han constituido un aspecto importante del conflicto en torno a la neoliberalización. A continuación elaboro estas ideas considerando el intento de los Comités Patrióticos de desarrollar espacios y tiempos de oposición al proyecto neoliberal en Costa Rica.

\section{COMITÉS, TRADICIONES, Y CIUDADANÍA EN COSTA RICA}

Un aspecto importante de los Comités Patrióticos es su manera de unir organización e incidencia en las escalas del barrio y de la nación. Esta "nueva forma de hacer la política" contrasta con la estructura dominante que vincula los barrios con los partidos nacionales establecidos (el Partido Liberación Nacional, o PLN, y el Partido Unidad Social Cristiana, o PUSC), tanto en su forma de articular las distintas escalas, como en la forma de práctica política que promueve. Precisamente por su carácter innovador, los Comités Patrióticos han tenido que luchar con cuestiones de escala en diálogo con las tradiciones e instituciones políticas existentes.

El trabajo de los Comités Patrióticos ha sido en buena medida intentar cambiar la cultura ciudadana y su organización de escala al mismo tiempo: fomentar una cultura que enfatiza el 
reclamo en vez de la petición, así como buscar formas de posibilitar una participación popular más directa y autónoma en las escalas del barrio $y$ de la nación.

La política "comunitaria" representa una forma principal de participación política en Costa Rica. En una encuesta nacional realizada por Ciska Raventós en 2007, "un tercio [respondieron que] había participado en una organización comunal, grupo de vecinos o junta de mejoras de la comunidad en los últimos cinco años" (cita sin fecha: 14$)^{2}$. Al mismo tiempo, varios estudios publicados en las últimas décadas argumentan que el control de este espacio de participación por los partidos dominantes limita su potencial de servir como una fuerza autónoma para reclamos populares (Cayetano, 1989; Valverde et ál., 1989; cf. Alvarenga, 2005). Por su parte, activistas de los Comités Patrióticos conciben este trabajo como una lucha en contra de un clientelismo omnipresente, y particularmente en relaciones políticas formadas desde los barrios. Como dijo un integrante en una reunión cantonal de Comités Patrióticos en Montes de Oca en marzo de 2008, "perdimos el referéndum por la misma razón que perdemos [las elecciones en] los cantones: por el clientelismo, por los bonos de vivienda, por la percepción de que si tengo una buena relación con el candidato, estoy bien".

Mis observaciones en los Barrios del Sur indican que la política de barrio sí está en buena medida dominada por prácticas políticas particularistas, personalistas, $y$ clientelares. A partir de abundante evidencia de un clientelismo "duro" por la repartición de bonos de vivienda, placas de taxi, y oportunidades de "chanchullos", quisiera señalar la importancia de las prácticas más sutiles en que individuos o pequeños grupos hacen peticiones a funcionarios de los ministerios públicos en aras de resolver sus problemas, facilitadas por las relaciones personales. Esta ubicua política personalista de petición, que conduce a relaciones personalistas y clientelistas, constituye una lógica que se ve replicada en diversos ámbitos; en la descripción del presidente de la

$2 \quad$ En esta encuesta "domiciliaria fueron entrevistadas un total de 1596 personas con una muestra representativa en todo el país" (Raventós, cita sin fecha: 2-3).
República de su "amistad" con el pueblo (Arias, 2008), tanto como en un programa de radio que pone a las personas que llaman en contacto directo con las autoridades que puedan resolver sus problemas.

Por cierto hay otras tradiciones que dan forma a la política de barrio. Patricia Alvarenga (2005) ha rescatado una tradición de lucha desarrollada por las organizaciones comunales en torno al precio y accesibilidad de los servicios públicos, que logró una incidencia directa en la escala nacional en la huelga de pagos de 1983. Organizaciones comunales de los Barrios del Sur tienen un alto perfil en esta historia. Sin embargo, actualmente esta tradición particular de "rebeldía ciudadana" (ibid: xxvii) parece predominar en otras esferas, como en algunos de los sindicatos importantes del sector público (ANEP, los del ICE) y en los Comités Patrióticos ${ }^{3}$. Sugiero, además, que el énfasis en la escala nacional refleja la prevalencia de la clase media y el sector público en los Comités Patrióticos.

\section{EL REFERÉNDUM SOBRE EL TLC Y EL SURGIMIENTO DE COMITÉS PARA LA ESCALA NACIONAL}

Los Comités Patrióticos nacieron a la luz del primer referéndum en la historia de Costa Rica para decidir la entrada o no de este país al CAFTA, el primer referéndum en la historia del país. La controversia sobre el TLC ha sido fundamentalmente un conflicto en torno a la política de escala. El debate público giró en torno a tres temas: (1) las condiciones del acceso al mercado estadounidense, (2) la habilidad del Estado de manejar los recursos nacionales y la economía doméstica; (3) la viabilidad de las instituciones públicas de bienestar encargadas de la salud (CCSS), la electricidad y telecomunicaciones (ICE), y los seguros (INS). Los argumentos empleados por ambas partes eran complejos $y$ variados, aunque en términos generales, la

Por ejemplo, en contraste con lo sucedido en 1983, las organizaciones comunitarias de los barrios populares de San José no parecen haber jugado un papel clave en las manifestaciones en contra del Combo en 2000. 
campaña del No se enfocó en la defensa de la escala nacional, mientras el Sí enfatizó la prioridad de las escalas regionales y globales de circulación transnacional.

Estos argumentos ocurrieron en medio de una geografía económica y política concreta que implicaba intereses $y$ prioridades distintas. Sin poder abarcar la variedad de este escenario complejo, me enfoco en los Comités Patrióticos como una parte importante del movimiento del No. Primero, observo que estos comités se constituyeron por personas más involucradas con el mercado o el Estado Nacional. Había un predominio de trabajadores o pensionados profesionales del sector público nacional, $y$ un número significativo de estudiantes de universidades $y$ colegios públicos. En cuanto al sector privado, los integrantes tendían a venir de las profesiones liberales o de pequeñas y micro empresas orientadas al mercado nacional, mientras que empleados de empresas con intereses transnacionales eran escasos ${ }^{4}$.

Hay una evidente correspondencia, o tal vez más bien una falta de contradicciones, entre los "intereses materiales" de estos grupos y la defensa de instituciones estatales y mercados nacionales (véase Cordero, 2005). Sin embargo, basado en lo expresado en numerosas reuniones, conversaciones, $y$ entrevistas, es evidente que la participación en los Comités reflejó sobre todo un compromiso sincero con un proyecto del "estado bienestar" y regulador 5 . Planteo que

Mis datos etnográficos sobre la conformación de los Comités Patrióticos recibieron alguna confirmación con una encuesta hecha por Ciska Raventós (distinta a la anteriormente citada), aunque no era posible conseguir una muestra con representatividad estadísticamente confiable. La encuesta incluyó 259 personas en 16 comités. (Los resultados todavía no se han publicado).

Sostengo que la alta participación del sector público en oposición al TLC, por ejemplo, no puede ser reducido a un sencillo "interés material" en proteger sus empleos. En adición a las prioridades expresadas en los discursos tantos públicos como privados, el TLC prometía más cambiar la forma que reducir el tamaño del estado. Con la excepción importante del ICE, no había una expectativa de despido masivo en el sector público. Sin embargo, por cierto la experiencia de un sostenido declive, la mayor parte de los activistas de los Comités Patrióticos pueden ser caracterizados como intelectuales orgánicos del proyecto estado nacional: personas que han ejecutado el trabajo intelectual requerido por este proyecto, lo cual ha contribuido a formar su visión del mundo (véase Gramsci, 1971). En el contexto del referéndum, estos intelectuales del estado bienestar (profesores de los colegios y las universidades, funcionarios públicos calificados y profesionales), se convirtieron en intelectuales políticos en defensa de lo nacional.

De acuerdo con este rasgo intelectual, la práctica más característica de los Comités ha sido una pedagogía política participativa: organizando charlas $y$ talleres; produciendo $y$ distribuyendo volantes, boletines, y sitios web; tocando puertas $y$ hablando con vecinos. Interpretar el debate sobre el TLC requería un enorme esfuerzo intelectual por parte de todos, porque abarcó asuntos tan diversos como: los derechos de autor y patentes; el estatus legal de inversionistas extranjeros; el estatus legal comparativo de la Iniciativa de la Cuenca del Caribe y el CAFTA; los acuerdos internacionales relacionados con el acceso a recursos marinos y submarinos; $y$ los efectos esperados de la competencia China en textiles o de inversión extranjera en telecomunicaciones, entre muchos otros. Participantes describen el referéndum como una experiencia de aprendizaje intensiva en campos altamente dispersos.

El trabajo intelectual altamente participativo, que caracterizaba a los Comités en el referéndum, fue posibilitado por una organización particular que vinculó acción en escalas distintas dentro de una red descentralizada. Mientras los Comités actuaban sobre un asunto de política nacional (con implicaciones transnacionales), estaban organizados en escalas más pequeñas, como la del barrio. La coordinación entre los Comités era extraordinariamente libre, y ocurrió principalmente por participación en listas de correo electrónico u otras redes parcialmente

en la época neoliberal, en la condición de instituciones públicas y las condiciones de empleo que ofrecen, constituye una parte importante de su evaluación del TLC (véase Cordero, 2005). 
coincidentes como las de los sindicatos, ONG's, $y$ partidos opositores, o por vínculos formados en el mismo proceso de oposición al TLC. Debido a esta descentralización, nadie ha podido hacer un censo completo de los Comités, pero personas involucradas en varios intentos de articulación estiman que había cerca de doscientos justamente antes del referéndum, distribuidos por todas las regiones del país (en zonas rurales parecen haberse formado generalmente donde había números significativos de profesionales $y$ disponibilidad de internet).

Los Comités se formaron autónomamente y por procesos distintos según la comunidad en que se dieron, en el contexto de un creciente movimiento en contra del TLC y un amplio despertar de compromisos fervorosos, que posibilitaron una multitud de iniciativas de base. La formación de "Comités Patrióticos" como tal ocurrió entre mayo y julio de 2007, después de la aprobación del referéndum en abril del mismo año. Pero la oposición al TLC ya llevaba varios años de organización y crecimiento, incluyendo, notablemente, el rápido surgimiento del Partido Acción Ciudadana (PAC) como una segunda fuerza electoral con una plataforma anti-TLC $y$, una marcha de decenas de miles de personas en febrero. Este movimiento tenía sus propias raíces en un marcado aumento de oposición a la neoliberalización desde mediados de los noventa, incluyendo una huelga importante del magisterio en 1995 y una ola de protesta nacional en el 2000 contra la ley del "Combo ICE", que privatizaría la energía y las telecomunicaciones (véase Clark, 2001; González y Solís, 2001; Solís, 2002; Sojo, 2004; Almeida y Walter, 2007). Esta década de movimiento dejó un tejido social entre opositores al neoliberalismo, tanto como cambios en ideologías y subjetividades que contribuyeron a la formación de los Comités.

En aproximadamente la mitad de los casos que conozco (cinco de nueve), comités de apoyo a partidos opositores (sobre todo del PAC) eran importantes en la composición inicial de Comités Patrióticos. En otros casos, el comité tenía una escuela, una $\mathrm{ONG}$, o una familia como su núcleo inicial. Pero la formación de un Comité Patriótico siempre implicó ampliar el grupo e incluir nuevas personas, frecuentemente desconocidas previamente. Las charlas, debates, $y$ otros eventos públicos visibilizaron a los Comités $y$ atrajeron a nuevas personas. Otras personas se involucraron por medio de listas de correo electrónico o redes personales ${ }^{6}$. El alto nivel de preocupación por el TLC impulsó a personas a tomar iniciativas y buscar oportunidades de involucrarse en la campaña. En el caso del Comité Patriótico Juanito Mora (vea abajo), tres de las personas principales del comité ya habían empezado a trabajar solas por la campaña del No, diseñando $y$ distribuyendo volantes $y$ afiches antes de que se integraran en el comité.

Al reunir a personas con una diversidad de afiliaciones, $y$ la autonomía con que se formaron, no había un grupo externo que dominara a ninguno de los Comités que he conocido, ni mucho menos alguna dirigencia única para los Comités en la escala nacional. Aún el papel de comités del PAC en muchas instancias de organización de los comités no implicó mucho en términos de articulación nacional ${ }^{7}$. Todos los comités involucraron a gente de varios partidos, sindicatos, $y$ movimientos, $y$ en su discurso interno enfatizaron constantemente en la independencia de los comités de cualquier instancia de organización política existente.

La incidencia en la escala nacional ocurrió primero por la suma de fuerzas a escalas menores. Pero también había una práctica política concebida más directamente en términos de la

Vale notar que participación amplia en listas de correo electrónico en sí indica un grado importante de organización. Aunque no ha sido posible desarrollar este tema en esta ponencia, creo que la importancia de estas listas muestra que los Comités Patrióticos se formaron con base en procesos de organización social de más larga trayectoria, aunque su articulación de personas particulares y su forma de organizar eran novedosas.

$7 \quad$ El PAC es un nuevo partido que no cuenta con la estructura e identificación sólida de los partidos más establecidos. Muchos de los activistas de los Comités manifestaron que su apoyo al partido era una decisión motivada principalmente por su oposición al TLC, y yo vi las relaciones entre estos activistas de los Comités y el partido en la mayoría de los casos como algo muy conyuntural. Después del TLC, muchos se alejaron del partido por lo que vieron como una oposición inconsistente al TLC. 
escala nacional. A pesar de la ausencia de una estructura consolidada, surgió una red vinculando a los opositores del neoliberalismo fuera de las formas de participación existentes en esta escala. Los Comités no limitaban su práctica a las comunidades en que se organizaron. Comités del área metropolitana de San José, por ejemplo, fueron a las provincias y zonas rurales, donde suponían que la dominación de los partidos históricamente mayoritarios, las relaciones clientelistas, $y$ los medios masivos, sería absoluta. Lo nacional era concebido nuevamente como un campo de acción, de forma que impulsó la formación de relaciones políticas $y$ luchas compartidas entre personas de lugares distintas. Según el estimado de varios activistas dentro y fuera de los comités esto es uno de los logros más importantes del movimiento del No. A continuación considero con más detalle cómo funciona este nuevo ámbito político nacional en el periodo después del referéndum.

La descentralización del movimiento nacional dejó espacio para una participación abierta, posibilitando que cada Comité definiera su propia forma de organización, plan de trabajo, volantes, etc. Entonces, fue precisamente esta configuración de escala (comités de los barrios dentro de una libre red nacional), la que hizo de los Comités una estructura política novedosa, $y$ permitió el empoderamiento que los integrantes sintieron con la oportunidad de participar autónoma, activa, $y$ creativamente en este proceso histórico y nacional.

\section{EL ESPACIO-TEMPORALIDAD \\ DE LA NACIÓN EN UN TIEMPO \\ DE GLOBALIZACIÓN NEOLIBERAL}

La defensa de lo nacional constituyó el centro de unidad para el movimiento del No. Subsumió diferencias en políticas de escala entre los que favorecían la renegociación del tratado, los que veían tal acuerdo de "libre" comercio con los Estados Unidos como no necesario, y los que favorecían otro tipo de alineamiento internacional como la integración latinoamericana. El énfasis en la nación, como "el pueblo", también en buena medida subsumió las diferencias de clase en el país al nivel ideológico, aunque el pueblo era generalmente representado en una lucha con una oligarquía de "políticos empresarios", quienes, en alianza con el capital transnacional, usarían su poder sobre el estado para imponer un tratado que les permitiría "vender al país".

Defender la nación implicaba al mismo tiempo basarse discursivamente en su espaciotemporalidad, que tiene la ventaja de un fuerte arraigo cultural en el nacionalismo, pero al mismo tiempo, la desventaja de ser comparativamente abstracto. Al otro lado, la campaña del Sí, por su control de recursos económicos y espacios claves como el lugar de trabajo, tenía una ventaja clave al poder manejar una campaña de varias escalas simultáneamente: cuando ofrecían bonos de vivienda a cambio de apoyo electoral, o hicieron amenazas de cierre de fábricas y despidos, redujeron una campaña nacional sobre un tratado transnacional a los espacios y tiempos más inmediatos y concretos de casa, barrio y trabajo. En comparación, los Comités Patrióticos, y el movimiento del No parece un tanto atrapado material $y$ discursivamente en el espacio $y$ tiempo de la nación. Sin embargo, el movimiento del No también tenía maneras de manejar la relación entre lo nacional y las escalas más inmediatas. Movilizó miles de ciudadanos para entrar en conversación con sus vecinos, familias, $y$ amigos. También intentó realizar lo nacional concretamente, primero explicando los resultados esperados en instituciones $y$ mercados nacionales $y$ el impacto de esos cambios en la vida diaria, y segundo, poniendo un énfasis particular en una interpretación ética de lo que ha sido emblemático de la esencia de la nación.

La iconografía del movimiento del No reflejaba la centralidad de la defensa de la nación y el énfasis en realizarlo más concretamente en la ética de las personas. Juanito Mora y Juan Santamaría, héroes de la "Campaña Nacional" en contra de los Filibusteros estadounidenses, eran resucitados como sujetos ubicuos de la iconografía del No. Aunque estas figuras son iconos poco controversiales del nacionalismo oficial, adquirieron un significado distinto como ejemplos de resistencia contra el imperialismo norteamericano en el presente. $Y$ si bien pueden representar la nación porque existen en la misma temporalidad imprecisa de la imaginada esencia del 
"pueblo costarricense", el movimiento del No les dio nueva vida como ejemplos de virtud heroica relevantes a los dilemas éticos del momento ${ }^{8}$. Igualmente, la bandera nacional superpuesta en un corazón, que se convirtió en el principal símbolo del No, sirvió para posicionar lo nacional en la ética, el corazón siendo siempre un símbolo de la buena voluntad hacia otras personas ${ }^{9}$.

El futuro del "patrimonio nacional" implicó a la nación en una forma más material. Un aspecto central del desarrollo del estado costarricense en la segunda mitad del siglo veinte fue la creación de instituciones que vincularon ciudadanía con derechos a servicios proveídos por el estado. Instituciones públicas de bienestar como el CCSS (salud y pensiones) y el ICE (telecomunicaciones y electricidad) se convirtieron en bases de la legitimidad del estado y ejes de la identidad nacional, asociada con la promoción de una valoración de éticas de "solidaridad" y servicio al público. Para los opositores del TLC, la defensa de la nación era también la defensa de las fuentes de bienestar y las éticas de compromiso social y la aplicación de razón técnica al bien común. Por lo tanto la campaña del No estaba fuertemente arraigada en las fuentes tradicionales de la legitimidad del estado. La campaña del Sí no negaba estos valores, sino argumentaba que las instituciones de bienestar eran seguras y que mejorarían con el tratado.

Una controversia paralela se desarrolló en torno a la autoridad y legitimidad del estado y los actores políticos. Para el No las instituciones estatales habían sido "secuestradas" por un grupo corrupto de "empresarios políticos". Este hecho es supuestamente evidente en el mal manejo $y$ autoritarismo en las instituciones públicas, tanto como en las decisiones del Tribunal Supremo de Elecciones y la Sala IV (la corte constitucional) que favorecían al Sí. La campaña del Sí hizo su

Sobre el tema de la temporalidad de los estados nacionales modernos, véase e.g. Benjamin, 1940; Anderson, 1983; Koselleck, 1990; Chatterjee, 2004: 3-26.

Había un anuncio del No que propuso esto en términos explícitos, hablando de la diferencia entre dos tipos de corazones: un corazón del No que se preocupa por los demás, y uno del Sí que "quiere poder". propia apelación a lo nacional, asociándose con la autoridad del Estado y representando a los del No como amenazas al orden y a la democracia, financiadas por los gobiernos de Hugo Chávez y Fidel Castro. Un memorándum del gobierno promoviendo una "campaña del miedo", filtrado durante el referéndum, pone esta estrategia en términos explícitos (Chacón y Chacón, 2007).

La campaña del Sí también apeló a una temporalidad del progreso nacional y global; la imperativa de llevar progreso a la nación ${ }^{10}$, y el recurrido a una representación del progreso humano global que supuestamente traerían el TLC y sus cambios institucionales. Había en este discurso temporal una mezcla de apelaciones a la esperanza y al miedo. La esperanza prometida era más inversión, más empleos, oportunidades empresariales, $y$ la promesa de convertir esto en mejoramiento de la perspectiva de vida de cada uno. El miedo era la amenaza de la pérdida de lo anterior. Pero como señalé, el Sí tenía simultáneamente la ventaja de poder trasladar estos medios ( $y$ de menor grado, estas esperanzas) a escalas más inmediatas, por la amenaza de cierres y despidos o la promesa de un bono de vivienda.

Dentro del movimiento del No prevalecía otra versión de la temporalidad nacional y global del progreso. Para el No, el TLC no ofrecía la promesa de progreso, sino la amenaza de una profundización del "neoliberalismo", entendido como una ola global que amenazaba la historia $y$ futuro del progreso nacional. En el caso de los Comités Patrióticos, el neoliberalismo ha sido entendido por muchos en términos de su propia experiencia de la crisis, los recortes, y la volatilidad a partir de los años ochenta. La mayoría de los integrantes de los Comités son mayores de cuarenta años y representan a una generación de movilidad social. Muchos de ellos, tal vez la mayoría, provienen de orígenes más populares (obreros y campesinos) y ascendieron a la clase media con el auge del Estado benefactor. Atribuyen su ascenso social a este estado, y recuerdan a las instituciones de bienestar antes de su declive en los años ochenta $y$

10 Fernando Coronil (1997) y David Nugent (1997) proveen discusiones importantes del papel de la modernización en la formación de nacionalismos en América Latina. 
noventa. Como clases medias estatales han visto un declive en su condición económica relativa y en la seguridad de sus empleos (Cordero, 2005).

También el movimiento del No tenía sus propias políticas de esperanza. Una era la más públicamente expresada, de un progreso "solidario". Pero además, dentro del movimiento había una esperanza de una transformación de las relaciones de poder que gobiernan al país, una esperanza producto de estar en un movimiento novedosamente participativo y inesperadamente poderoso. Era frecuente oír que la "gente se ha despertado". Frases comunes como: "si gana el No, el presidente va a tener que renunciar", o "vamos a tener una constituyente", reflejaban un sentimiento de transformación política inminente. Al mismo tiempo, el trabajo constante de reunirse, hacer volantes, tocar puertas, organizar charlas y presentaciones de vídeos, transformó rutinas básicas de la vida $y$ de las relaciones afectivas. La percepción de que las estructuras políticas fundamentales estaban en cuestión y de que el futuro era abierto a la acción transformativa, se juntó con la profunda transformación de la vida cotidiana que al sumergirse en la campaña implicaba, reforzar un sentimiento de estar en un tiempo de cambios profundos. Mientras para algunos era una primera experiencia de participación política intensiva, y para otros formó parte de una trayectoria más larga que tendía a incluir participación en las manifestaciones en contra del Combo en el 2000, fue frecuente describir la experiencia en términos de transformación personal ${ }^{11}$. Igualmente, el hecho de entrar en una nueva, participativa esfera pública parece haber tenido efectos transformadores en las vidas de muchos de los integrantes, tal vez más marcadas para mujeres que enfrentan más obstáculos para entrar en esferas públicas existentes. En al menos algunos casos, involucrarse en esta nueva esfera pública tuvo efectos

La sugerencia es que representó un tiempo algo "liminal" en el sentido del Antropólogo Victor Turner. Los tiempos liminales son tiempos de suspensión de estructuras sociales y culturales que producen cambios profundos en las identidades. Yang (2000) aplica esta teoría a los efectos transformativos de movimientos sociales. Gracias a Ciska Raventós por la sugerencia que el referéndum creyó tal temporalidad liminal. de empoderamiento en la vida privada (las relaciones familiares $y$ de pareja).

\section{DESPUÉS DEL REFERÉNDUM: EXPERIMENTOS EN POLÍTICA DE ESCALA}

El día del referéndum, el siete de octubre 2007, dejó otra vez, un sentimiento de tiempo transformado. Cuando ganó el Sí por una ventaja de 3,4\%, el mismo estatus "histórico" del referéndum se convirtió en una fuente de dolor, un sentimiento de pérdida profunda, una ansiedad sobre el futuro del país, y una indignación sobre el manejo de la campaña y las condiciones desiguales en que se dio. Los que se mantenían activos en el movimiento - una proporción muy alta de los comités con los cuales tengo la mayor familiaridad - entraron en tiempos extraordinarios: un tiempo de reacción al voto mismo, seguido por el tiempo desorientador de la "agenda de implementación".

En la estela inmediata del referéndum, los Comités Patrióticos mantenían un enfoque firme en la escala nacional. Pero mientras continuar su impacto en la escala nacional era la meta común, había una divergencia sobre las estrategias y tácticas por seguir, que generó nuevos conflictos. Muchos querían mostrar un rechazo a los procesos "fraudulentos" del referéndum. También la temporalidad particular de la agenda de implementación, que según el gobierno requirió la aprobación de trece leyes en un plazo de tres meses, parecía abrir una posibilidad de derrotar el tratado o incidir en la forma de su implementación, sea por movimientos en las calles, por demandas legales, o por otros referéndums. La resistencia al Combo parecía dar un ejemplo de cómo incidir exitosamente a escala nacional por medio de protestas, huelgas y bloqueos. Pero la legitimidad pública del proceso del referéndum pesaba, nunca era claro que tan real era el plazo de tres meses, $y$ aunque se organizaron docenas de manifestaciones y paros solamente en la capital, nunca tomaron la fuerza esperada por sus organizadores.

Al mismo tiempo había otro proyecto paralelo, que para muchos era más importante: articular los Comités en una red de escala nacional que serviría como una nueva fuerza social capaz 
de mantener una resistencia continúa en contra del neoliberalismo. En algunos casos, el interés en este proyecto parece haber sido motivado por proyectos partidistas y electoreros, pero en general, había un deseo de crear una nueva forma de hacer la política. Participantes demandaban procesos horizontales, participativos y altamente democráticos, $y$ dedicaban horas tras horas $y$ día tras día en discutir la manera de hacerlo. En medio del dolor y de la indignación, seguía la esperanza de cambiar la forma de hacer la política, alimentada por el sentimiento de representar una nueva y poderosa fuerza social.

Pero por diferencias personales y políticas los intentos de articular una estructura nacional no avanzaron mucho. Las reuniones grandes $y$ asambleas eran caóticas y a veces conflictivas. Paulatinamente, los Comités Patrióticos transformaron su política de escala, promoviendo articulaciones entre comités en escalas más pequeñas (los cantones), o dirigiéndose más localmente, los distritos o barrios. En vez de las evidentes dificultades en movilizar "el pueblo" se argumentaba con frecuencia que las políticas locales eran más "concretas", y contribuirían a formar vínculos con "la gente" en una forma que las políticas más abstractas de la escala nacional no permitía ${ }^{12}$.

Sin embargo, ninguno de los comités activos que conozco ha abandonado la escala nacional. Además de protestas dirigidas a asuntos nacionales, los Comités Patrióticos se han involucrado en recoger firmas para referéndums sobre leyes de propiedad en semillas y acceso a recursos hídricos. Por otro lado, hay intentos de fomentar una coalición unificada para promover un programa anti-neoliberal en las elecciones nacionales de 2010, y de crear maneras de hacer aportes participativos a este programa. En los barrios, los Comités seguían con el trabajo de pedagogía política por medio de volantes, boletines, $y$ charlas, pero también por intentos de fomentar nuevas prácticas políticas a escalas locales que impulsarían un cambio en la cultura

12 Me parece también que corrientes localistas, comunitarias, $y$ autonomistas en la izquierda contemporánea han tenido influencia en impulsar un enfoque político más local, pero la evidencia directa para este planteamiento es poca. ciudadana. Por último, hay rastros de la conformación de nuevas redes nacionales basadas en la suma de varias luchas locales en problemáticas compartidas.

Estos esfuerzos de encontrar un lugar en el cual se puede construir una política nueva no han sido nada fáciles. Reuniones tienden a durar dos o tres horas, una vez cada semana, sumado a cualquier acción concreta que el comité decida ejecutar. Muchos comités han pasado por etapas de indecisión, en las que parecían estar ocupados nada más que en conversaciones infructuosas. Los comités se han reducido paulatinamente, aunque el número de personas con un compromiso por seguir con el proyecto de los comités sigue siendo sustancial. De cara a estos desafíos, durante el 2007 se ha presentado una amplia diversidad de iniciativas e intentos de definir nuevas formas de hacer la política. Explorar nuevas políticas de escala ha sido una parte fundamental de este esfuerzo. Abajo discuto algunos casos específicos de estos intentos.

\section{PRIMER EJEMPLO: EL COMITÉ PATRIÓTICO JUANITO MORA}

El Comité Patriótico Juanito Mora está asentado en un barrio popular de la Zona Sur de San José13. Los miembros del Comité se diferencian de la mayoría de la gente del barrio por la formación universitaria y profesional, aunque la mayoría vienen de orígenes obreros y tienen raíces familiares profundas en el barrio. Después del referéndum personas nuevas entraron al Comité, incluyendo un grupo de jóvenes universitarios, y el comité se consolidó con reuniones más regulares, cotizaciones, y el nombre "Juanito Mora".

Al inicio era uno de los Comités más activos en la oposición a la agenda de implementación, pero, en parte por la influencia de un señor con cuarenta años de experiencia en organización comunitaria, se empezó a dar prioridad a la participación en el barrio. Como muchos comités se ha dedicado a actividades informativas: creó un sitio web, vendió periódicos alternativos

13 Por razones de confidencialidad no empleo el nombre de este barrio. 
en el barrio, organizó una charla sobre la "crisis alimentaria”, y empezó a desarrollar un boletín.

Pero Juanito Mora ha sido más excepcional en su práctica de organización comunal. El comité fue clave en organizar una respuesta de la comunidad al asesinato de una niña de ocho años; trabajó con la escuela del barrio para realizar una marcha en contra de la violencia y para promover prácticas educativas dedicadas a la no violencia. Además ha impulsado la organización en torno a la calidad de infraestructura y servicios públicos en la comunidad, en particular la carencia de un puente peatonal para cruzar la carretera que divide el barrio. Para la primera reunión llegaron aproximadamente cincuenta personas, la mayoría mujeres adultas mayores $y$ de una composición de clase marcadamente popular. Los participantes estaban notablemente indignados por la falta de este puente, ya que se había demandado durante los últimos veinte años. Se formó un nuevo comité, PASSE, para promover la lucha por el puente, $y$ en las semanas siguientes se realizó una manifestación en el lugar del actual cruce informal. El nuevo comité también inició una campaña de corazones negros para marcar sitios de inseguridad generada por falta de servicios e infraestructura.

Con esta campaña el Comité Juanito Mora entró en relación con los otros comités que funcionan en el barrio. Muchas de las mujeres (y los pocos hombres) que llegaron al PASSE se relacionaban con otros comités, que representan las preocupaciones de una parte del barrio o aún de una sola calle ${ }^{14}$. Algunas participaban o habían participado en las Asociaciones de Desarrollo de la zona, y el PASSE consiguió acceso al salón comunal de una de estas Asociaciones para sus reuniones. Estos comités se caracterizan por una práctica política muy distinta a la de Juanito Mora, en la cual prevalecen el escribir pliegos, visitar ministerios, $y$ acumular cartas debidamente selladas que prometen solucionar los problemas. En general, se ven las relaciones con las personas que toman decisiones como un recurso importante; algunas de las señoras que llegaron a las reuniones se encontraron sorprendidas y decepcionadas al

El barrio principal, que tiene decenas de miles de personas, se divide en otros barrios más pequeños, cada uno con un nombre y un grado de identidad propia. darse cuenta que los integrantes del comité Juanito Mora no quisieron seguir este tipo de política. Las prácticas más contestatarias que advocaron los de Juanito Mora, como la manifestación por el puente o la campaña de pintar corazones negros en las calles, eran recibidas con una mezcla de sorpresa, escepticismo y entusiasmo. Era ampliamente aceptado que las cartas $y$ visitas realizados por los varios comités durante veinte años no habían logrado su meta. "En este país hay que presionar a los políticos" se convirtió en una consigna de aceptación general en las reuniones.

Hay otras maneras en que la organización de PASSE significó un encuentro entre orientaciones y prácticas políticas distintas, diferencias que evidencian algunas de las formas de control político que operan en los barrios. Existió un momento de tensión cuando se reveló que el propósito originario del Juanito Mora había sido oponerse al TLC, mientras algunas de las otras personas asistentes se identificaron como partidarios del Sí, incluyendo una representante de la asociación de desarrollo que proveía el salón comunal para las reuniones de PASSE. Esta misma expresó que "jamás" hubiera abierto el salón para el Comité Patriótico, "porque no comparto sus ideales", aunque también explicó que dado que el grupo estaba trabajando por "cosas de la comunidad", ella estaba dispuesta a dar su permiso. En otra reunión la junta directiva de la misma asociación dejó claro que podía dar su apoyo a la organización de eventos culturales, e incluso presionar al gobierno para mejorar la infraestructura de la comunidad, pero que no podía involucrarse en nada de "política" ("ni fanatismos religiosos"), aunque en la misma conversación hablaron de sus relaciones con los regidores y el alcalde. Además de una distinción más o menos sutil entre políticas prohibidas y permitidas, me pareció que estas declaraciones evidenciaron una clara distinción entre realizar prácticas opositoras en la escala nacional y en la escala del barrio ${ }^{15}$. Estas distinciones reflejan, en

15 Hay un evidente interés por parte del gobierno nacional en las expresiones del descontento en este barrio. El día de la manifestación para el puente, dicen que aparecieron dos representantes de un grupo con un nombre parecido al "comité presidencial para el manejo comunal de desastres". No pude hablar con ellos personalmente este día. 
parte, como los partidos dominantes han limitado y canalizado la participación política autónoma y las manifestaciones del descontento en las pequeñas escalas. Tales demandas aisladas pueden ser postergadas o cumplidas con relativamente pocos recursos, mientras se forma relaciones útiles con líderes potenciales, las cuales facilitan la hegemonía de los partidos en la clave escala nacional (vea p. ej. Alfaro, 1990).

El énfasis político en el barrio tiene su equivalente en la expresión de identidad. En las reuniones de PASSE prevalecía un discurso de identidad de barrio sobre las identidades (nacionales o internacionales) de clase, tanto como la identidad del "pueblo" nacional que predomina en el discurso de los Comités Patrióticos. Los integrantes explicaban y justificaban su presencia en términos de su residencia y sus raíces en el barrio, y mostraron una identificación fuerte con ello. Aunque hay un aspecto de identidad de clase en el contraste que hacían entre ellos y la "gente de Escazú o los Yoses" (barrios más adinerados, quienes, se observaba, seguramente tenían su basura recogida y sus alcantarillas tapadas), es significativo que tal identificación de clase parece estar en su mayor parte articulada a la escala del barrio.

El espacio y tiempo de lo "concreto" parece también tener importancia en establecer la prioridad del barrio como esfera de acción política. En el caso de la falta del puente peatonal lo concreto del asunto es casi literal: Hay que cruzar una carretera evidentemente construida para facilitar la rápida circulación de automóviles sin tomar en cuenta las vidas de los peatones. Las señoras sienten su propia lentitud frente a los carros, $y$ les preocupa la excesiva rapidez y arriesgada impulsividad de sus nietos. Ha habido muertos, recordados en la memoria comunal. Y además, hay veinte años de promesas postergadas.

El Comité Juanito Mora se ajustó en su práctica al espacio-temporalidad del barrio, pero siempre con una mirada a escalas más grandes. Los volantes y otras materias del comité rescatan la historia del barrio, pero siempre con referencia a la importancia de lucha y a problemáticas nacionales e internacionales. La campaña de corazones negros es otro ejemplo. Aunque evidentemente inspirados por los corazones del movimiento del No, se transformaron en un símbolo para la política del barrio. Al quitar los colores de la bandera los corazones ya no hacían referencia a lo nacional. Y en contraste con los corazones del No, estos se posicionaron para marcar lugares de inseguridad inmediato: al lado de un basurero informal o una alcantarilla no tapada, o donde debería de haber un puente peatonal. Aunque mantenían la referencia a lo ético que está implícito en el corazón como símbolo, se dejó el vínculo de lo ético con la patria para hacer referencia a dilemas más inmediatos: en las palabras del señor del comité Juanito Mora quien originó la idea, estos corazones negros representaban "los corazones negros que no hacen nada para la comunidad". Pero al mismo tiempo los corazones negros servían como intento de crear una consciencia más sistemática de los problemas del barrio. Ampliamente difundidos, generarían un reconocimiento de la cantidad de faltas de infraestructura y mantenimiento, articulando por lo menos una visión de escala del barrio en conjunto. Y por último, el objetivo explícito era fomentar una conciencia más crítica, que los residentes vean, noten y piensen en los problemas.

Igualmente, el objetivo de organizar una manifestación por la ausencia del puente no era solamente lograr que un puente se construya. Fue también encaminado a promover otra forma de ciudadanía, una que estaría dispuesta a manifestarse para reclamar sus derechos: la tradición de "rebeldía ciudadana" (Alvarenga, 2005) intentando transformar la tradición dominante, que enfatiza peticiones civiles a personas de autoridad. Por este énfasis en cambiar la cultura ciudadana y la forma de hacer política en el barrio sigue partiendo de una esperanza de cambio político en escalas más grandes, conforme con compromisos políticos nacionales y pan latinoamericanistas. El comité busca tender un puente entre escalas, rescatando a las necesidades auto-definidas de la comunidad por un lado, $y$ haciendo un trabajo de pedagogía política por el otro, en la cual la acción tiene un papel clave.

\section{SEGUNDO EJEMPLO: SARDINAL}

Y EL CONFLICTO SOBRE EL AGUA

El Comité de defensa del Agua de Sardinal no es un "Comité Patriótico"; no surgió para 
oponerse al TLC ni a la neoliberalización a escala nacional, sino para tomar acciones en un asunto de interés para la comunidad. Pero la lucha en Sardinal provee un ejemplo importante de cómo los Comités Patrióticos han intentado definir su papel político en el periodo después del referéndum y la agenda de implementación.

Sardinal es un pueblo rural y relativamente pobre, en una zona costera de Guanacaste caracterizada por un vertiginoso desarrollo de bienes raíces y turismo. De lo que me contaron personas de la comunidad, no tiene ninguna historia de política contenciosa ${ }^{16}, y$ hubo muy poca actividad en el transcurso del referéndum. Pero algunos empezaron a hacer preguntas cuando vieron tres grandes pozos en construcción, trabajo que, según cuentan, procedió solamente por las noches. Una líder del eventual Comité de Defensa me contó, que al inicio ella se tranquilizó un poco viendo que eran construidos por la AyA, la empresa estatal de aguas, porque se supuso que el proyecto era entonces para el bien público. Pero dentro de poco vieron que el proyecto también incluía tubos gigantes rumbo a la costa, donde se ubican los proyectos de desarrollo inmobiliario. Cuanto más averiguaron sobre el proyecto, les pareció peor; el proyecto era financiado por las inmobiliarias, quienes comerciarían el acceso del agua. Además, un estudio encargado por gobiernos locales, incluyendo la Asociación de Desarrollo, indicó que los estudios requeridos no se habían realizado, y que no había ninguna garantía en torno al abastecimiento de agua a la comunidad.

Se realizaron varias manifestaciones en contra del proyecto, y en una ocasión la policía disparó gas lacrimógeno a manifestantes de la comunidad. El conflicto ganó la atención del público nacional en la prensa, en la internet, $y$ en los discursos de opositores al gobierno. Se realizaron más marchas con personas de la comunidad y la región, así como un número menor de ambientalistas e integrantes de Comités Patrióticos y otras

16 Aunque Marc Edelman (1992) documenta algunas luchas para preservar tierras comunales en los años cuarenta, de las conversaciones que he tenido con personas de la comunidad, estos eventos parecen no conformar una parte de la memoria popular activa. organizaciones del valle central. Representantes de la comunidad y partidos de oposición en la asamblea nacional (notablemente el partido izquierdista, Frente Amplio) plantearon denuncias legales al proyecto, logrando que la Sala IV y el gobierno municipal declararan un paro provisional a las obras.

La red de los Comités Patrióticos parece haber jugado un papel importante en trasladar el conflicto a la escala nacional. Desde el principio el Comité de Defensa contaba con el apoyo de los integrantes de un Comité Patriótico cercano, y ellos emplearon la red de los Comités para difundir información y conseguir apoyo, junto con otras redes de organizaciones nacionales y regionales en las que participaban. Desde temprano este Comité Patriótico había empezado a dirigir la atención hacía políticas locales; cuando otros Comités se dedicaron a movilizar en oposición a la privatización del mercado de telecomunicaciones, ellos empezaron una campaña de "rescatamos Guanacaste", con el propósito de enfocarse en asuntos regionalmente relevantes como el acceso al agua y a las playas, y el pésimo estado de los caminos. Por su posicionamiento relativo a organizaciones regionales y nacionales, $y$ por su enfoque en luchas de la región, eran especialmente capaces de movilizar en escalas múltiples.

El conflicto en Sardinal rápidamente se convirtió en una causa principal y punto de referencia para los Comités Patrióticos y otros opositores al neoliberalismo, e impulsó iniciativas a escala nacional. Animó a diversos actores sociales a interesarse por la situación de una comunidad en otra parte del espacio nacional, e impulsó la creación de nuevas redes que unieron a diversos actores preocupados por el actual manejo de recursos hídricos, incluyendo un grupo de Comités Patrióticos ya involucrados en la defensa de cuencas en Heredia. Algunos comités del valle central (incluyendo el Comité Juanito Mora) se movilizaron para enviar sus integrantes a las protestas y proveer apoyo material. Una iniciativa para recoger firmas para un referéndum por una nueva ley nacional de aguas parece haber recibido un impulso importante.

Hay evidencias de que la política de escala dentro de Sardinal también cambió por 
la campaña y el contacto con el movimiento nacional del "No". Los sardinaleños tienen una evidente identificación con la comunidad, la cual es invocada por los líderes al reclamar el agua bajo su suelo. Al mismo tiempo, activistas del Comité de Defensa también invocan otra política de escala que define el agua como la propiedad de "todos". Desde este punto de vista, el problema es más bien que la comunidad está en riesgo de quedarse sin agua por su desperdicio al regar canchas de golf, céspedes, $y$ piscinas en hoteles $y$ casas de lujo, un argumento que enfatiza un reclamo de clase y nación más que uno de comunidad. Los dos tipos de llamamiento pueden ser invocados por la misma persona en la misma ocasión. Sin embargo, parece probable que el apoyo de personas desde afuera ha servido para animar el énfasis más nacional.

El proceso de lucha y el encuentro con activistas parece haber despertado la conciencia política de muchos de los sardinaleños. Varias personas involucradas en la lucha (de Sardinal $y$ de lugares cercanos) contaron que la percepción de la comunidad hacia líderes locales y al gobierno nacional se había hecho mucho más crítica desde que inició el proceso. Por ejemplo, un integrante del Comité de Defensa me explicó que siempre había apoyado a los candidatos de los partidos mayoritarios, y que había votado por el Sí al TLC, posiciones de las de que se arrepentía y atribuyó a su "ignorancia", por no haber visto la corrupción de los partidos dominantes por los intereses económicos poderosos.

Representantes del estado nacional también intentaron incidir en la cultura política $y$ ejercer liderazgo intelectual para frenar la resistencia al proyecto. Es importante destacar que este esfuerzo se basó, en gran parte, sobre intentos de movilizar solidaridades locales. El ministro de la presidencia (hermano del actual presidente) protestó en contra del involucramiento de "grupos de la extrema izquierda" desde afuera de la comunidad (R. Arias, 2008). A partir de la exageración del papel de actores externos y la caracterización de su orientación política. Señalo más bien, el hecho irónico de que una figura de la política nacional se oponga al involucramiento de actores externos en una comunidad subnacional. Esta actitud revela una concepción de orden (o control) político en el cual, el manejo de la relación entre estas comunidades y la escala nacional es un derecho reservado a los partidos dominantes e instituciones del Estado. Este tipo de discurso parece tener arraigo: escuché a policías de Sardinal empleando un discurso parecido, para desacreditar las palabras de un activista que venía de otra parte de Guanacaste, para asistir a una manifestación. Se nota también que dicho argumento es cercano al reclamo del agua hecho en términos comunitarios.

El AyA entró más activamente en la comunidad. Organizó una celebración en que proveyó comida, música, y entretenimiento para los niños, mientras distribuyó volantes favorables al proyecto. Representantes del AyA también condujeron una "encuesta" puerta por puerta, en la cual, según reportajes de activistas de la zona, recogieron una lista de nombres de residentes quienes afirmaron haber sido "informados" sobre el proyecto. Surgieron reportes de funcionarios del AyA diciendo a personas en comunidades cercanas que la gente de Sardinal estaba trabajando en contra de su propio acceso al agua y el progreso de la zona. Por último, voceros favorables al proyecto dieron charlas públicas, en la iglesia y otros lugares.

Los integrantes del Comité de Defensa desarrollaron tácticas para combatir o neutralizar la influencia de los representantes del AyA y las inmobiliarias en la comunidad, tácticas que son relevadores por sí mismas en cuanto al tipo de poder que esperaban enfrentar. Denunciaron el intento del AyA de ganar su afecto con comida $y$ entretenimiento como una grave falta de respeto. Insistían en que todas las reuniones con representantes del gobierno o los inversionistas fueran abiertas y públicas, $y$ mostraron una preocupación con el manejo transparente de los recursos del movimiento. Al ver un par de estas interacciones, era notable que los jerarcas del AyA $y$ los representantes de los inversionistas prefirieran reunirse con pequeños grupos de "líderes" "capaces de tomar decisiones independientemente". En vez de la determinación del comité de realizar reuniones abiertas, invariablemente cancelaron la reunión.

Por último, señalo que esta controversia también ha implicado temporalidades 
contradictorias. Promotores del proyecto lo han defendido como necesario para el "progreso", lo cual es en parte, un argumento concreto sobre oportunidades en el futuro próximo, y en parte, una apelación a una narrativa temporal que tiende a caracterizar a cualquier oposición a un proyecto de infraestructura, como una contracorriente a la historia global (Chatterjee, 2004: 4-8). Por su parte, opositores del acueducto invocaron a otras temporalidades más específicas a este proyecto. Obviamente incluyó la amenaza de estar sin agua en un plazo no conocido. La afirmación del AyA que habrá agua por "veinte años" provocó indignación: "y para nuestros hijos, ¿qué?” se preguntaron. 0 , como expresó una líder del Comité de Defensa, "quiero que mis hijos recuerden a su mamá como alguien que luchó para que tengan agua" (entrevista, 20 de julio, 2008). De manera general, la forma de "desarrollo" en la región no se considera como una sencilla encarnación del progreso. Un integrante del comité, quien trabaja en el turismo, me explicó que esperaba un desarrollo más "equilibrado", con atención al medioambiente y la generación de oportunidades para los pobladores de la zona, en contraste con la situación actual que pone en peligro los recursos naturales, mientras ofrece los mejores empleos y las ganancias a personas del Valle Central y a los extranjeros. Escuché opiniones similares de otras personas involucradas.

\section{ALGUNAS CONCLUSIONES}

Hasta cierto punto lo sucedido en estos dos casos parece confirmar el planteamiento de que los sectores más populares en Costa Rica se movilizan en torno a asuntos "concretos" en espacio-temporalidades inmediatas, mientras lo nacional es más una preocupación de las clases medias. Pero también sugiere que esta caracterización no es estática, $y$ que el encuentro entre personas con perspectivas del espacio-temporalidad distintas puede ser productivo y transformador en formas no esperadas, en parte por impulsar cambios en los horizontes de las personas involucradas. La historia de Costa Rica, tanto como la de otros países, muestra la posibilidad de mover las preocupaciones inmediatas hacia una conciencia política nacional e internacional (Gould, 1990; Nash, 1993 y 2001; Edelman, 1999 y 2005).

En su intento de definir una práctica política opositora al neoliberalismo, los Comités Patrióticos, después del referéndum, han empezado un arduo proceso para definir una política de escala que les permitiría cambiar el proyecto hegemónico ejecutado por el estado nacional. Han desarrollado la capacidad de moverse en las escalas de barrio y nación al mismo tiempo, algo que puede ser un requisito para construir un movimiento que una a las clases populares con sectores de la clase media, comprometidas con el fortalecimiento del estado de bienestar y el desarrollo de una política más participativa. Este trabajo no es sencillo; encontrar las clases populares en su terreno significa, en primer lugar, enfrentar las formas políticas que actualmente delimitan la participación popular, como las Asociaciones de Desarrollo y el "solidarismo", $y$, en segundo lugar, ajustarse al espacio-temporalidad de vidas frecuentemente vividas como una serie de crisis. Sin embargo, es probable que solo de esta forma se puedan transformar las relaciones de fuerza. Y existen indicaciones de que tal proyecto pueda ser viable. El sostén ideológico de las clases dominantes puede ser menos firme de lo que frecuentemente se supone, y el sistema partidario vigente durante la segunda mitad del siglo veinte está en un declive evidente. Por último, planteo que una lección importante de moverse a la escala del barrio es que la polarización entre un "Sí" y el "No", que parece tan real a las personas más metidas en la política nacional, no refleja las divisiones sociales fundamentales. Definir los límites de movilización y organización popular en estos términos, seria circunscribir las posibilidades de los dos.

\section{FUENTES CITADAS}

Almeida, Paul y Erica Walker. "El avance de la globalización neoliberal:una comparación de tres campañas de movimientos populares en Centroamérica". Revista Centroamericana de Ciencias Sociales IV (1), julio. 2007: 51-75. 
Alvarenga Venutolo, Patricia. De Vecinos a Ciudadanos: Movimientos Comunales y Luchas Cívicas en la Historia Contemporánea de Costa Rica. San José y Heredia: Universidad de Costa Rica $y$ Universidad Nacional, 2005.

Anderson, Benedict. Imagined Communities: Reflections on the Origin and Spread of Nationalism. Londres, 1983. Verso.

Arias Sánchez, Óscar. "La mejor medicina del mundo". Diario Extra. Opinión. 2 de Junio, 2008. En: <http://www.diarioextra. com/2008/junio/02/opinion03.php> [fecha de acceso: 2 de junio 2008].

Arias Sánchez, Rodrigo. 2008. "Extrema Izquierda está detrás del Acueducto en Sardinal". Diario Extra. Nacionales, 29 Mayo, 2008. En: <http://www.diarioextra. com/2008/mayo/29/nacionales11.php> [fecha de acceso: 29 de mayo, 2008].

Auyero, Javier. Poor People's Politics: Peronist Survival Networks and the Legacy of Evita. Durham, NC: Duke University Press, 2000.

Benjamin, Walter (1940). "On the Concept of History". Walter Benjamin: Selected Writings 4, 1938-1940. Cambridge, MA: Harvard University Press, 2006.

Brenner, Neil. "Globalization as Reterritorialization: The Re-Scaling of Urban Governance in the European Union”. Urban Studies 36 (3). 1999: 431451.

Cayetano Mora, Jorge. La Organización Comunal y DINADECO, 1964-1987. San José, ICES: 1989.

Chacón, Vinicio y Lorna Chacón. "El Sí Juega la Carta del Miedo". Semanario Universidad 551, año XI. 6 de Septiembre, 2007. En: $<$ ht p://www.semanario.ucr. ac.cr/archivo_digital /nuevas e diciones/ediciones $2007 /$ M09Setiembre_2007/1728_SET06/index. htm> [fecha de acceso: 5 de noviembre, 2008].

Chatterjee, Partha. The Politics of the Governed: Reflections on Popular Politics in Most of the World. Delhi: Permanent Black, 2004.

Clark, Mary A. Gradual Economic Reform in Latin America: the Costa Rican Experience. Albany, New York: SUnY, 2001.

Cordero Ulate, Alan. "Clases Medias y Movimientos Sociales en Costa Rica". Revista de Ciencias Sociales 109-110. 2005: 157-166.

Coronil, Fernando. The Magical State: Nature, Money and Modernity in Venezuela. Chicago: University of Chicago Press, 1997.

Edelman, Marc. The Logic of the Latifundio: the Large Estates of Northwestern Costa Rica since the Late Nineteenth Century. Stanford: Stanford University Press, 1992.

Peasants against Globalization: Rural Social Movements in Costa Rica. Palo Alto: Stanford University Press, 1999.

"Bringing the Moral Economy Back In...to the Study of 21st-Century Transnational Peasant Movements". American Anthropologist 107. 2005: 331-345.

González Ortega, Alfonso y Solís Avendaño, Manuel. Entre el Desarraigo y el Despojo: Costa Rica en el Fin de Siglo. San José, Costa Rica: Universidad de Costa Rica, 2001.

Gould, Jeffrey L. To Lead as Equals: Rural Protest and Political Consciousness 
in Chinandega, Nicaragua, 1912-1979. Chapel Hill and London: University of North Carolina Press, 1990.

Gramsci, Antonio. "The Intellectuals". Selections from the Prison Notebooks of Antonio Gramsci. Quintin Hoare y Geoffrey Nowell Smith, eds. London. Lawrence and Wishart. 1971: 5-23.

Koselleck, R. Futures Past: On the Semantics of Historical Time. Keith Tribe, trans. MIT Press, 1990.

Lomnitz Adler, C. Exits from the Labyrinth: Culture and Ideology in the Mexican National Space. Berkeley and Los Angeles: University of California Press, 1992.

Marston, Sallie. "A Long Way from Home: Domesticating the Social Production of Scale". Scale and Geographic Inquiry. Eric Sheppard y Robert B. McMaster, eds. Malden, MA and Oxford, Blackwell. 2004: 170-191.

Marston, S. and N. Smith. "States, Scales and Households: Limits to Scale Thinking? A Response to Brenner". Progress in Human Geography 25 (4). 2001: 615619 .

Molina Alfaro, Eugenia. "Repercusiones PolíticoOrganizativas del Acuerdo Político firmado entre los Frentes de Vivienda y el Estado durante la Administración Arias Sánchez". [Tesis de Maestría en Sociología]. Universidad de Costa Rica, 1990.

Nash, June. We Eat the Mines and the Mines Eat Us. New York: Columbia University Press, 1993.

Mayan Visions: The Quest for Autonomy in an Age of Globalization. New York and London: Routledge, 2001.
Nugent, Daniel. Modernity at the Edge of Empire: State, Individual, and Nation in the Northern Peruvian Andes, 1885 1935. Stanford, CA: Stanford University Press, 1997.

Raventós, Ciska. "Cultura Política y Participación en Costa Rica". Artículo inédito producto de la investigación Participación Política y Electoral 2006. Instituto de Investigaciones Sociales, Universidad de Costa Rica. Sin fecha.

Smith, Neil. Uneven Development: Nature, Capital and the Production of Space. Oxford y Nueva York: Basil Blackwell, 1984.

"Geography, Difference and the Politics of Scale". Postmodernism in the Social Sciences. Joe Doherty, Elspeth Graham, y Mo Malek, eds. MacMillan: Nueva York and London, 1992.

"Scale Bending and the Fate of the National". Scale and Geographic Inquiry: Nature, Society and Method. Malden, MA y Oxford. Blackwell, 2004: 192-212.

Sojo, Carlos. "Líneas de Tensión: Gestión Política de la Reforma Económica. El Instituto Costarricense de Electricidad (ICE) y la Privatización de Empresas Públicas”. Politicas Sociales. 2004: 3-57.

Solís Avendaño, Manuel. "Entre el cambio y la tradición: El fracaso de la privatización de la Energía y las Telecomunicaciones en Costa Rica". Revista de Ciencias Sociales. 2002: 33-48.

Swyngedouw, Erik. "Neither Global nor Local: 'Glocalization' and the Politics of Scale", Spaces of Globalization: Reasserting the Power of the Local. Ed por K. R. Cox. Nueva York. The Guilford Press, 1997: 137-66. 
"Scaled Geographies: Nature, Place and the Politics of Scale". Scale and Geographic Inquiry: Nature, Society and Method. Malden, MA y Oxford. Blackwell, 2004: 129-153.

Tilly, Charles. Democracy. Cambridge y Nueva York: Cambridge University Press, 2007.
Valverde, José Manuel, Elisa Donato, y Rolando Rivera. "Movimientos Sociales Populares y Democracia". Rojas M, et ál. Costa Rica: Democracia Inconclusa. San José, Costa Rica: DEI, 1989.

Yang, Guobin. "The Liminal Effects of Social Movements: Red Guards and the Transformation of Identity". Sociological Forum 15 (3). 2000: 379-406. 
